\title{
Istanbul's single truth: a sustainable policy and a sustainable capital
}

\author{
S. Turgut \\ Department of Urban and Regional Planning, \\ Yıldız Technical University, Turkey
}

\begin{abstract}
In an international dimension, Istanbul, an assertive city where the scientific society accepts it to be of universal value, has been claiming its identity as a global city throughout the centuries. The current process of this city, which incorporates many rapid and striking changes, is in jeopardy. In the long run, it is moving towards a point that would threaten the city with rapid and alarming steps. This paper will focus on two projects that constitute two of these steps. It will try to explain the ecological and cultural heritage based threats that these two projects cause for the sustainability of the city. The first one is a project that was currently debated for Istanbul, also a mega transportation project - North Marmara Highway and Third Bosphorus Bridge, and the second one is Golden Horn Subway Transition Bridge, which goes above Golden Horn and is the first subway transition bridge in Turkey. This paper will evaluate the risks and threats, which the first rapidly constructed project creates in the northern parts of the city every day. The second project to be discussed, the Golden Horn Subway Bridge, will be considered with particular regard to its negative effect on the Historical Peninsula and the Süleymaniye silhouette. As a result, considering the risks that these kinds of interferences in the city's identity could cause in the long run, the fact that the factors leading to the investment decisions are the "capital's demand" and "projects that are away from scientific acceptance" instead of "sustainability", "cultural heritage and identity" or "protection-usage balance" will be discussed. Keywords: İstanbul, sustainable city, Third Bosphorus Bridge, İstanbul silhouette.
\end{abstract}




\section{Introduction}

In Istanbul's macro form, particularly the investment projects of foreign capital and projects that are globally demanded like big infrastructure projects (mega projects) are effective. It is apparent that there is no planning system that could restrain or lead the effects that are taken notice of, nor could they define and limit the "red lines" and threshold of the city. The blockage of this system that could not be controlled by local state or policies is the fact that this system lost its "constitutionalism" almost completely.

At this point, it is useful to remark that it is possible to see the following when the planning practice in Turkey is examined: Plans can present a manner in which the protection identity and sustainability are denser in the definition process of decisions and spatial policy. However, in the application process, it can be seen clearly that the upper-scaled acceptances and principles change almost entirely with maneuvers and autonomous decisions of the central government. In other words, a development that is totally against the plan decisions can be observed. This process, which also opens the door for political patronage and legal revisions, completely turns the planning doctrines and urbanization principles upside down, and announces the sole boss as "the devastating power of the capital".

Considering these, Istanbul is in a very unfortunate place. On one hand, it is the shining star of the global capital and powers, and on the other hand it comes forward as an important identity value. However, the fact that this process was not able to make a coordinated, consistent and sustainable bond with planning and planning management, in the long run, has a potential danger of pushing the city into important deadlocks, or suffocating the living areas and leaving them breathless.

For instance, included in this paper, North Marmara Highway and Third Bosphorus Bridge transition is not seen in the Istanbul Environment Regulation Plan, 2009 or in Istanbul Transportation Master Plan, instead the route that this axle is situated on is separated as the areas that are defined as the areas that are required to be under protection (İstanbul Metropolitan Municipality, 2009). This structure poses danger eminently for a city like Istanbul, which has extremely important values in terms of nature and history.

\section{Historical marks of Istanbul}

Istanbul, situated in two sides of Istanbul Bosphorus that unites Asia and Europe like a fairytale, is an old but dynamic city, and perhaps one of the most exciting cities in the world. One of the oldest cities in the world, Istanbul, has a residential history of 300 thousand years, urban history of almost 3 thousands years, and a history of 1600 years as a capital city. Throughout the centuries, this city has welcomed different civilizations and cultures, and protected its cosmopolitan structure that includes diverse religions, languages and races, and became a unique mosaic in time. The diversities that created the colors of its cultural structure, also created the basis of excitement and freedom of the city. This "spice odorous" world city, succeeding in being a center of different cultures and in protecting its 
place in terms of power, is one of the main actors of the history of humanity from history to our day.

In Prof. Kuban's words, history of this city, in which the first residences have taken place 8000 years ago, and which continued its role as a political, economic and cultural capital city of East Mediterranean for 1.600 years, started with the marks of 3000 BC (Figure 1).

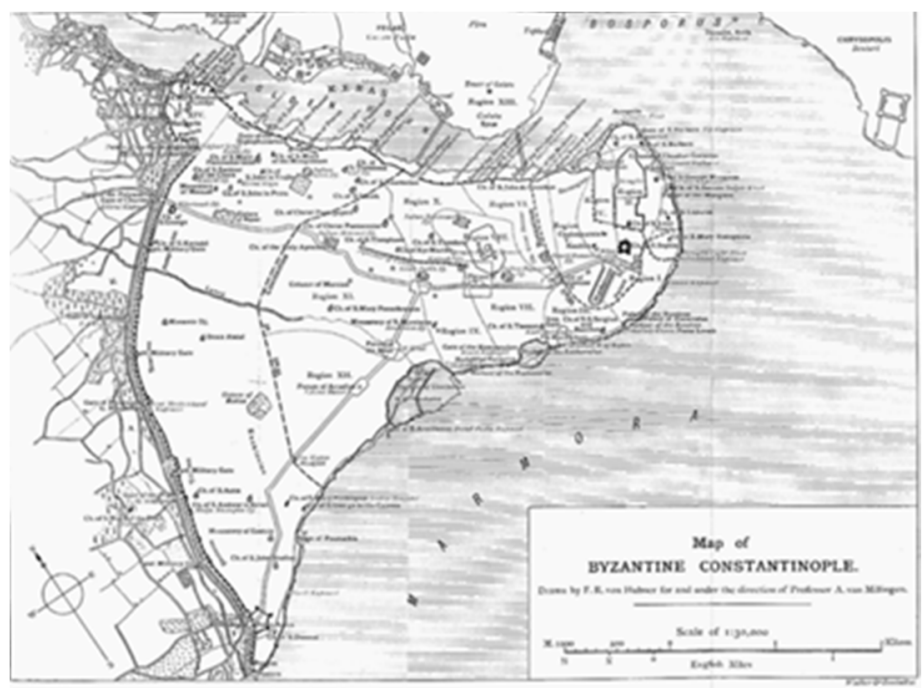

Figure 1: Byzantion - Constantinople.

The city, carrying the marks of Stone Age and Copper Age, became a city on which the Neolithic and Chalcolithic people left marks. According to Helen Mythology, 40 Greeks on a journey to Batumi debarked on today's Sarayburnu, as they passed through Bosphorus. They have not settled there or in Golden Horn, or in Chalcedon. In this era, Istanbul will have been established as an ancient Greek city-state and will have been called "Byzantion". In a short time period, it will have gained power and growth and will have been conquered by the central power then, Roman Empire. Romans made Byzantium more Latin and Byzantium became one of the most important cities of the Roman Empire. Its name was changed from Byzantium to Augusta Antonina. The basis of today's Istanbul was built in VII. Century BC [1].

The city goes under the domination of the Rome Empire in 196 BC. The emperor of the Rome Empire, Septimius Severus, includes Byzantion into the Roman Independency Declaration. Another emperor of the Roman Empire, Vespasian, made the city more Latin to make sure it stays bounded to the Empire in I. Century.

In this era, Istanbul's name was changed to Constantinople. It was also made the capital city of first the Roman Empire and then of Byzantium. The capital city of Byzantium, Constantinople developed as a city, dominating the Middle East for 1000 years. The history of Istanbul as a capital city started 65 years before the 
separation of the Roman Empire as East and West. Byzantion became the capital city of the Roman Empire with the order of Emperor Constantine the Great in 330 as "Nova Roma" (New Rome). The name of the city changes from Byzantium to Constantinople with the death of the emperor for his memorial. Constantinople, replaced Rome with its invasion and devastation, became the capital city of East Rome, which is the successor of the Roman Empire.

Constantinople, in 395, became the capital of the Byzantium Empire, which was established under the name of East Rome Empire in the beginning and then evolved to Byzantium with the fall of the West Roman Empire. In 1204-1261, Constantinople under the invasion of Latinos became the capital city of the Latin Empire.

After the Latin domination, Constantinople again became the capital of the Byzantium Empire until 1453. Istanbul was going to be the capital city of a great universal empire in this era and possess the land extended through three different continents for longer than 400 years.

After II. Mehmed, the universal (conqueror) Fatih Sultan Mehmet, conquered the city in 29 May 1452, and the Ottoman era started (www.istanbul.net.tr), tr.vikipedia.org.

Muslims named the city as "Konstantiniyye" but the Ottoman Empire used "Istanbul" instead. The city, invaded by the Allies of the I. World War in 13 November 1918, was liberated when the Turkish army entered the city on 6 October 1923.

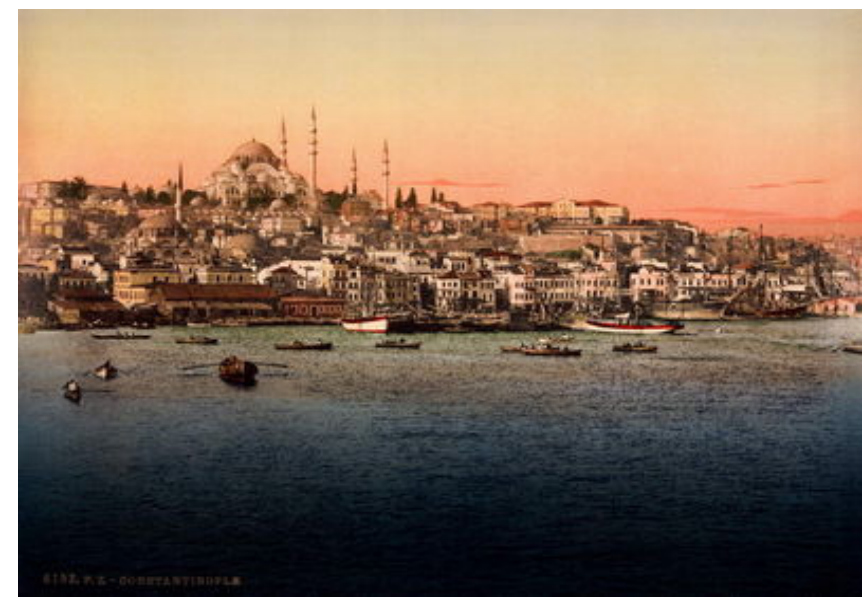

Figure 2: Süleymaniye Mosque silhouette.

Süleymaniye Mosque, included in this paper in terms of its silhouette values, is an artefact of XVI. Century and the visual feast that merges with the Historical peninsula in which the mosque is situated is one of the most determinant identity elements of Istanbul (Figure 2). 


\section{Nature's dedications to Istanbul and its position}

Since it is located on a special geography and it connects the Black Sea with Marmara Sea, and it possesses the Istanbul Bosphorus that separates Asia and Europe, the geopolitical importance of Istanbul cannot be overlooked. Istanbul is situated in the northwest of Turkey, through the Marmara shore and Bosphorus, surrounding the Golden Horn as well. The city mainly develops on an axle on the east-west route.

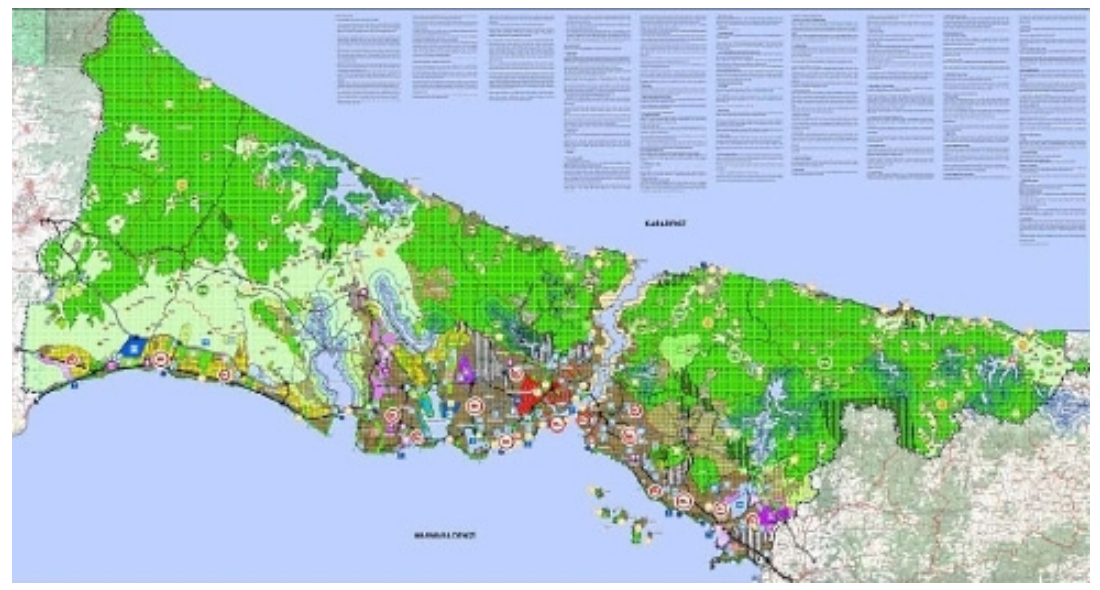

Figure 3: Istanbul linear form and natural thresholds, IBB 2009.

Residential areas usually head to the south through the Bosphorus and south shores and they are broken down to pieces with natural and artificial thresholds through the linear development (Figure 3) [2].

Especially the northern parts that carry extremely important spaces of the city and that open to Black Sea area, these catchment areas that have ecologicalbiological importance with the Floodplain Forests can be defined as an area with "featured vegetation". These areas are defined as the life support systems of the developed built-up areas through the Marmara Sea in the north

Istanbul harbors an important population of wild animals because of the green areas and water basins it possesses. Istanbul Bosphorus, which connects two rich ecosystems as Black Sea and Aegean, defines a transition area that is extremely rich in terms of fauna and flora. The same diversity and richness of breeds are also valid for the forest areas in the northern parts of the city. These routes on the bird migration paths are one of the most important bird migration paths in the world and they are among the areas that are put on the list with RAMSAR contract for they have to be protected because of their importance for water birds. World Wide Fund for Nature (WWF) specified the mentioned forests on this very sensitive geography as one of the most valuable "Hot Points" of "European Forests" in the urgency of protection, and took them under protection. This area, carrying the water reserve areas that provide water for Istanbul Metropolitan Area that is 
one of the most crowded metropolitans in the world, also creates the main components of the corridors and eco-zones, which have indispensable importance for the sustainable development of the city.

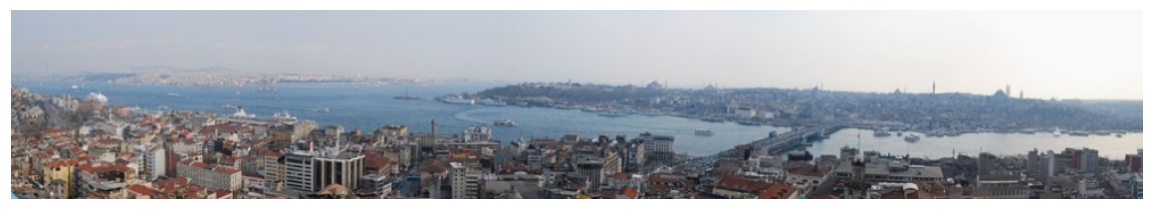

Figure 4: Istanbul after 2000s - Ivan Minariç, 2009.

Especially after 2000s, Istanbul commenced living a very rapid transformation process and it started shining as a city in which especially many international investments become alive. Formula races, mega transportation projects, grand shopping malls and residences, tourism facilities and areas could be some examples to this (Figure 4).

The most important point that should be underscored is the fact that these developments are not thought as plan integrity and that they almost entirely develop and apply in a structure that contradicts with the plan orders. Although it was exposed to some different criticism both about the plan making process and the plan orders, Istanbul Environmental Regulation Plan, approved in 2009, is agreed to be an undeniably important development constitution and the most important issue to be said on this plan is that it involves almost no big investment that shines in the present city even though the plan is in enforcement. This incredible contradiction is a subject that should be discussed, regarding the legislation of the plan, the incredible power of the capital and the demolition of the most important dynamics of the city. These investment decisions that overlook the orders of the plan with its principles, can cause serious danger primarily in sustainability, as well as the city's capacity, development limits, population growth, and the areas that should be protected, and many other fields.

\section{Two projects that threaten the city}

Two projects will be discussed in this paper as examples of these projects:

1. Third Bosphorus Transition - North Marmara Highway Project

2. Golden Horn Subway Transition and Bridge

Both projects separately contradict with the macro-form, ecological sources, protection-usage balance, sustainability, cultural heritage, protection of the identity, concrete and abstract cultural entities and sustainability, silhouette values and their protection, international protection approaches in the city and particularly the decisions of UNESCO. Although particularly the profession chambers within the Turkish Engineers and Architects Chamber, academic society, and planning authorities claim some of the media criticisms, the decisionmaking authorities and applicators do not accept these warnings. Projects continue 
to occur in the appropriate project process. The only accepted criterion is regarded as the project contribution to city's economics, and the fact that the ecological and cultural sustainability are under threat is denied. 1. The basis of Third Bosphorus Transition - North Marmara Highway Project is already done and the construction continues. 2. Haydarpaşa Station and Transformation Project is in the project process, and 3. Golden Horn Subway Transition and Bridge is done and open to business. Now, let's take a look at the risks that these projects carry.

\subsection{Bosphorus transition - North Marmara Highway project}

There are two main macro-form principles to be discussed in Istanbul.

1. Since all the life sources (forests, water basins and agricultural areas) are in the north of the Istanbul Metropolitan with its population over 15 million, the city should not grow too much to the north in order to protect these areas and Bosphorus. The city should grow parallel to the Sea of Marmara, on the east-west axle in a linear way.

2. The zone usage-transportation relation that would minimize the Bosphorus transition should be plotted. This situation, by creating a more balanced population and employment structure in between the two continents that would minimize the Bosphorus transportation from Anatolia for work, requires a multi-centered zone usage policy, which would remove the dependence of the two countries on each other. Legalized in 2009, Istanbul Environmental Regulation Plan with 1/100,000 scale that has a role as the basic guide for Istanbul to be a planned city embraced these basic approaches. The plan defends the following principle: "Developing Istanbul in a multi-centered (by jumping) based on the environmental sustainability principles and in a linear structure through the Sea of Marmara and the east-west axle, and taking the northern growth under control."

However, the effects of the first two bridge projects made on the Bosphorus before the third bridge are known and the fact that both bridges gave birth to many new problems instead of solutions in terms of transportation and planning is also very well know. Scientific societies claim that building a new bridge in the north is not an ideal solution, and the current blockage and chaos in the traffic would get even worse with this option [3].

Considering that the Third Bridge Project, planned to be done on the Bosphorus, would create its own traffic, augment the exhaust emissions, and would cause natural area devastation by triggering the construction of new roads and structures, it is foreseen that the effect of the heat island on Istanbul would augment. Heat island effect, clearly seen as the seasonal temperature goes above the normal line and the water in the dams reduces to critical levels, requires the planning of the water quality and quantity in the basins, the protection of the wholeness of the forest areas and the outdoor area usage in the rural areas if necessary (Figure 5) [4]. 

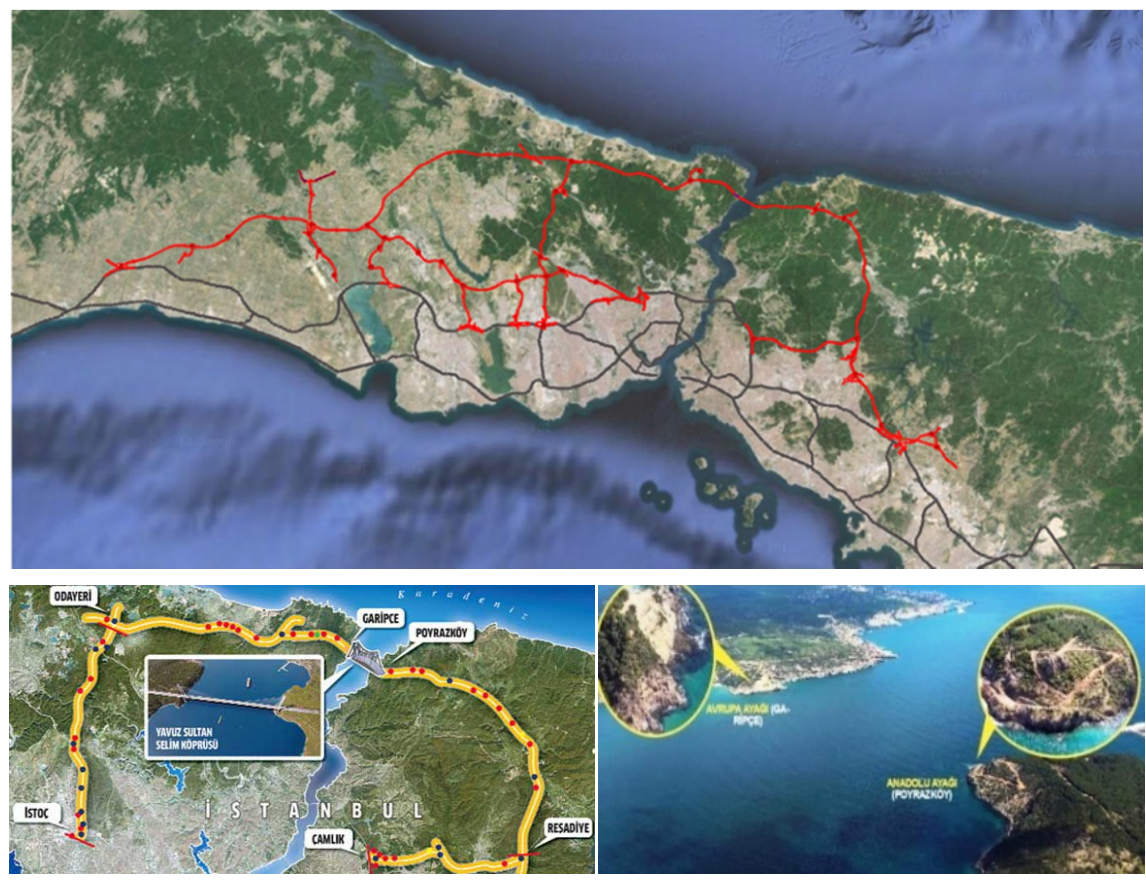

Figure 5: Third Bridge project connection motorways and destination.

Third Bosphorus Bridge connection paths - highways, whose majority rests in the catchments, would put intense construction pressure on important drinking water reserves of Istanbul, such as Ömerli, Elmalı, Darlık, Alibeyköy, Büyükçekmece, Sazlıdere and Terkos basins.

Although in 1935-1975 the population in Ömerli basin went from nearly 4000 to three times more at the end of 40 years and went above 10,000; post-1990, especially with the TEM highway effect the population augmented 50 times and approached 600,000 and this situation clearly reflects the population pressure on the basins that have vital importance in Istanbul.

The main and the secondary roads that would be connected to Third Bosphorus Bridge routes would have a negative impact on the northern forests and the wild life around. The highways surrounded by the barriers would directly ruin the habitats of wild animals and would limit the spread of the animal breeds in north of Istanbul. With the trees that are cut, the toxic carbon withholding would decrease and the forests that would be under pressure would reduce its efficiency. The new highways that would go in the interior forest would bring fire risk with them. Moreover, like any other highway, another problem would be the mal effect of the exhaust emissions on the environment [5].

In the $5 \mathrm{~km}$ long effect zone of the suggested Third Bosphorus Bridge and its connection paths in both directions, $34 \%$ of the private forests, $46 \%$ of the forest areas, $38 \%$ of the $2 \mathrm{~B}$ areas, $43 \%$ of the agriculture areas (Map 16) in Istanbul rest. In this effect zone that includes $18 \%$ of the strictly protected areas of the water 
basins in which physical construction - except for purification facilities - is forbidden, 29,000 hectares natural registered area (45\% of all the registered areas) are also under the risk of destruction. As a result of the planned $150 \mathrm{~m}$ long expropriation application for the bridge and its connection routes, in the area on which the route will pass, which would be affected directly and unconditionally, 680 hectare natural registered area, 931 hectare agriculture area, and 1453 hectare forest area that include more than 2.5 million trees would be ruined completely.
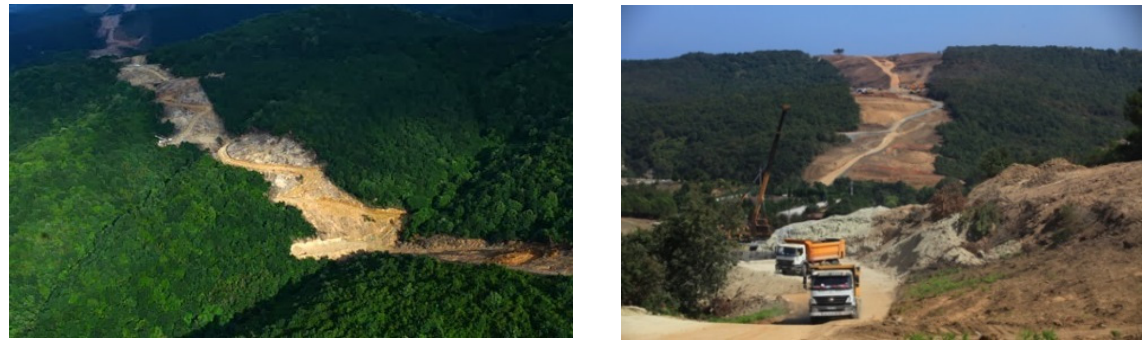

Figure 6: The Third Bridge building site view.

At the point that we arrived today, it is possible to see clearly how construction tears down the natural environment and ecosystem. The Third Airport Project that is suggested as the continuation of the same axle and is commenced by building the basis is another main factor that would trigger the laceration that would occur in the ecosystem of the city as the continuation of this project. It is an unacceptable step to open the foret area for construction by cancelling its status as a "protection forest" (Figure 6).

\subsection{Golden Horn transition subway and bridge}

The second project I will mention brings up the topic of how the first subway transition bridge of Turkey in between Galata and Eminönü that goes through Golden Horn, Golden Horn subway transition bridge, makes a negative impact on the silhouette and especially how it shadows the Suleymaniye Mosque (Figure 7).

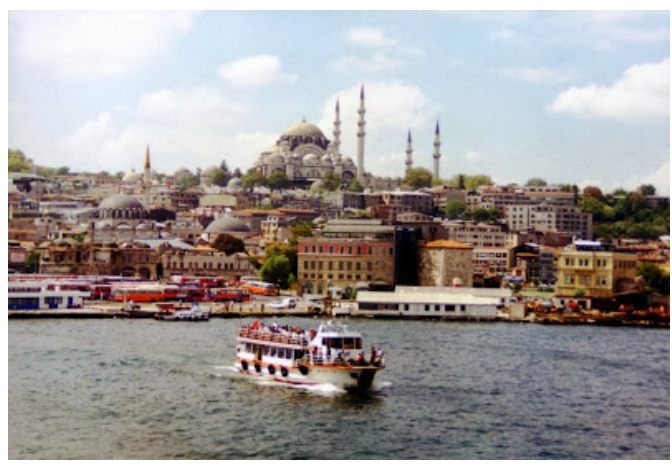

Figure 7: Suleymaniye silhoutte from Golden Horn. 
Süleymaniye Mosque, defined as the journeyman work of the great master Mimar Sinan, was constructed as a part of the Süleymaniye Complex that was consisted of library, hospital, hamam, hospices, madrasa, cemetery and stores. Süleymaniye Mosque is one of the most important pieces of the Classical Ottoman Architecture. Second biggest complex of Istanbul, Süleymaniye, on the most dominating hill of Istanbul, in Dr. Yenen's words is a spatial "climax" of an eminently rich planning, architecture and construction arts culture. Suleymaniye Mosque is accepted in international literature and is taken as the most basic reference points of the "Istanbul silhouette that is regarded with envy". Again, in Yenen's words, this silhouette that should be considered as almost a unique logo of Istanbul is being destructed in a serious level (Figure 8) [6].

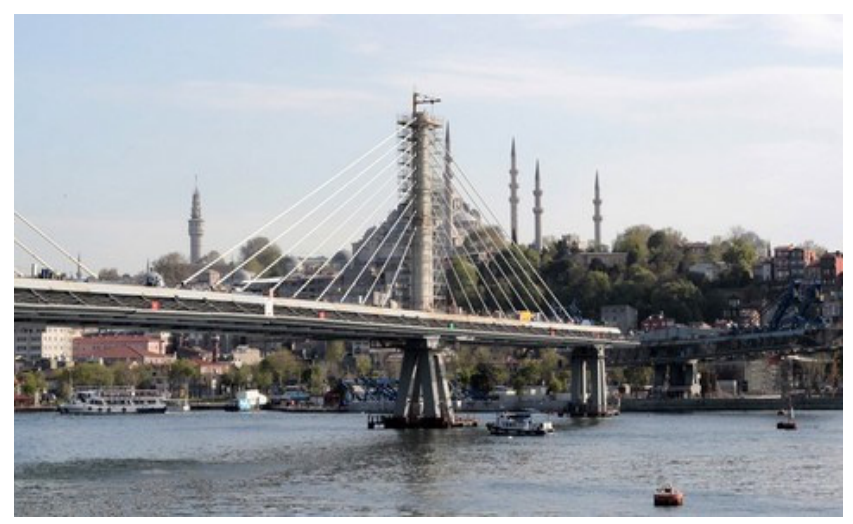

Figure 8: Suleymaniye silhoutte from Golden Horn after Golden Horn Subway Transition Bridge.

This structure and the unique silhouette of Istanbul is shadowed with a bridge construction, and is almost in an undetectable condition. Now, the Suleymaniye Mosque and Historical Peninsula silhouette that we hid behind a fan cabled subway bridge with two towers in Golden Horn, looking like a thick tape coming from Unkapani Bridge in the Historical Peninsula, is in a condition curtained with metal towers and cables up to Unkapani direction. During the project process, primarily UNESCO World Heritage Center, many NGO's and institutions objected and suggested many alternative solutions however the design and the making process of the bridge continued regardless these criticisms. Although UNESCO took 9 decisions in this process since the construction of the brige since 2006, and all of these 9 decisions claimed that this bridge would negatively affect Suleymaniye and the Historical Peninsula silhouette, which is a World Heritage, and thus this construction was wrong. However, the result has not changed. Monuments and Registered Areas Council Turkey National Comitee (ICOMOS) Administrative Board member Prof. Dr. Cevat Erder calls this bridge as "Bridge of Shame", but it took its place in Istanbul's silhouette and is open to service, regardless of the numerous objections of many authorities such as related scientific societies, architects, planners and graphic artists [7]. 


\section{Conclusions}

The two projects that I've tried mentioning in this paper are two current projects in Istanbul with different scales. Both took its place in Istanbul's agenda as the projects that contradicts with the cultural values, natural structure, and the heritage and that threathen the sustainabiliy of the city. The first one, Northern Marmara Highway and Third Bosphorus Bridge project threathens the ecosystem in the northern parts of Istanbuş. This project, which goes beyond threathening and "tears down" the northern ecosystems that nurture this grand metropolitan, turns the natural balance upside down, and puts the sustainability of the city in jeopardy. Second project, Golden Horn Subway Transition Bridge shadows Historical Peninsula and Suleymaniye Mosque, the masterpiece of an internationally accepted unique craftsman, with an extreme recklessness and it takes its place in the core of the city with a design that contradicts any protection principles and also with "logic".

It is easy to see that both projects overlook the sustainability of the city. Although it contadicts with the decisions that were accepted in the plan, the easy application of these two mega projects and the ignorance of their risks reflect a truth one more time as it pushes the justification of such a planning project and as it joins Istanbul as one of the areas made without principles.

In Istanbul Metropolitan Area, a development dynamic that ignores any scientific principle, urbanisation, planning, design and architecture principles, and protection-usage balances: 'capital-concentrated sustainability'.

\section{References}

[1] Kuban, D., İstanbul Bir Kent Tarihi, Tarih Vakfı Yayınları, İstanbul, 2004.

[2] IMM Istanbul Metropolitan Municipality Master Plan Report, İstanbul, 2009.

[3] http://www.spoist.org/dokuman/Raporlarimiz/spoist_3.koprurapor.pdf

[4] http://www.arkitera.com/haber/18050

[5] http://www.spoist.org/dokuman/Raporlarimiz/spoist_3.koprurapor.pdf

[6] http://www.bbc.co.uk/turkce/haberler/2014/02/140214halicmetrogecis.shtml

[7] Ayazoğlu, S., Arkitera, Haliç Metro Bridge, İstanbul, 2014. 